\title{
Heterogeneous Periostin Expression in Different Histological Variants of Papillary Thyroid Carcinoma
}

\author{
Simona Eliza Giusca, ${ }^{1}$ Cornelia Amalinei, ${ }^{1,2}$ Ludmila Lozneanu, ${ }^{1,3}$ \\ Delia Ciobanu Apostol, ${ }^{1,3}$ Elena Corina Andriescu, ${ }^{1,3}$ Alex Scripcariu, ${ }^{1}$ Raluca Balan, ${ }^{1}$ \\ Elena Roxana Avadanei, ${ }^{1}$ and Irina-Draga Căruntu ${ }^{1}$ \\ ${ }^{1}$ Department of Morphofunctional Sciences I-Histology, Pathology, “Grigore T. Popa” University of Medicine and Pharmacy, \\ Iasi, Romania \\ ${ }^{2}$ Department of Pathology, Institute of Legal Medicine, Iasi, Romania \\ ${ }^{3}$ Department of Pathology, "Sf. Spiridon" County Clinical Emergency Hospital, Iasi, Romania
}

Correspondence should be addressed to Cornelia Amalinei; cornelia_amalinei@yahoo.com

Received 7 April 2017; Revised 19 November 2017; Accepted 3 December 2017; Published 25 December 2017

Academic Editor: Fotios Loupakis

Copyright (C) 2017 Simona Eliza Giusca et al. This is an open access article distributed under the Creative Commons Attribution License, which permits unrestricted use, distribution, and reproduction in any medium, provided the original work is properly cited.

Background. Periostin (PN) epithelial and stromal overexpression in tumor pathology has been studied according to tumor growth, angiogenesis, invasiveness, and metastasis, but a limited number of studies address PN in thyroid tumors. Aim. Our study aimed to analyze PN expression in different histological variants of PTC and to correlate its expression with the clinicopathological prognostic factors. Material and Methods. PN expression has been immunohistochemically assessed in 50 cases of PTC (conventional, follicular, oncocytic, macrofollicular, and tall cell variants), in tumor epithelial cells and intratumoral stroma. The association between PN expression and clinicopathological characteristics has been evaluated. Results. Our results show that PTC presented different patterns of PN immunoreaction, stromal PN being significantly associated with advanced tumor stage and extrathyroidal extension. No correlations were found between PN overexpression in tumor epithelial cells and clinicopathological features, except for specific histological variants, the highest risk of poor outcome being registered for the conventional subtype in comparison to the oncocytic type. Conclusions. Our study demonstrates differences in PN expression in histological subtypes of PTC. Our results plead in favor of a dominant protumorigenic role of stromal PN, while the action of epithelial PN is less noticeable.

\section{Introduction}

Thyroid cancer represents less than $1 \%$ of total number of cancers, but during the last decades its incidence has been continuously growing, showing a dominant involvement of female sex and of young and medium ages [1]. Papillary thyroid carcinoma (PTC) is the most common histological type. Diagnosed in approximate $85 \%$ of cases [2], this histological type has a relatively good prognosis, distant metastases, and death being rare events.

Classically, the prognostic assessment of PTC relies, according to the WHO, on the following standard clinical and morphological factors: patients' age and sex, tumor size, histological variant, extrathyroidal extension, completeness of surgical resection, and occurrence of distant metastasis [1].
Tremendous progress has been made by genomics, transcriptomics, and proteomics in all types of cancers, including PTC, resulting in a switch over from traditional clinicopathological prognosis factors to new molecular prognosis markers.

The current trend in thyroid tumor pathology is to improve the grading framework by implementation of new molecular and genetic criteria that could explain the differences between the biological behaviors, quantified by low versus high PTC aggressiveness. Consequently, a large series of molecular markers have been investigated, but none of them has been yet validated and thus they are still considered as candidate prognosis factors. Therefore this issue is remaining a source of heated debate. 
As a component of the cellular matrix, periostin $(\mathrm{PN})$ has been recently included in the list of putative prognostic markers. PN is a cellular adhesion molecule, initially identified within the osteoblastic cellular line in mice [3] and named according its identification in periosteum and periodontal ligamentum [4].

PN is secreted by fibroblasts [5-7] and belongs to fasciclin-I family of proteins, functioning in cell-cell and cellextracellular matrix (ECM) interactions. It is located in fetal and normal adult organs, such as embryonic periosteum, placenta, heart valves, thyroid, adrenal glands, lung, stomach, colon, testicle, prostate, vagina, ovary, breast, and periodontal ligamentum [8-11].

PN epithelial and stromal overexpression in tumor pathology has been studied according to tumor growth, angiogenesis, invasiveness, and metastasis [10-14]. The published data are relatively limited but nevertheless they are supporting PN involvement in tumor progression in different locations, such oral [15] and head and neck carcinomas $[16,17]$, breast cancer [18-23], ovarian cancer [8, 12, 24-26], prostate cancer [27-30], renal cell carcinoma [31-33], pancreatic carcinoma $[34,35]$, stomach $[36-38]$, colon $[39,40]$ and hepatocellular carcinoma [13, 41, 42], non-small-cell lung carcinoma [43-46], malignant pleural mesothelioma [47], neuroblastoma [48], glioblastoma [49-51], and its association with aggressive phenotypes and poor prognosis $[7,10,13,14]$.

To the best of our knowledge, PN expression in thyroid tumors is scarcely reported in the mainstream publications.

Within this context, the present study aims to analyze PN expression in different histological variants of PTC and to correlate its expression with the clinicopathological prognostic factors.

\section{Material and Method}

2.1. Patients and Tissues. The study group is comprised of 50 patients diagnosed with PTC in "Sf. Spiridon" County Clinical Emergency Hospital and surgically treated by thyroidectomy with cervical lymph node dissection.

The clinicopathological features have been retrospectively documented from the medical files and included the following data: sex, age ( $<45$ and $\geq 45$ years old, resp.), tumor size, multifocality (number of foci), lymphovascular invasion, extrathyroidal extension (defined as microscopic presence of tumor cells beyond the thyroid capsule, into adipose tissue, skeletal muscle, or sizable vessels and nerves), lymph node metastasis, and tumor stages according to TNM and American Joint Committee on Cancer staging system [52].

All cases have been reassessed by two independent pathologists in order to identify the histological variant of PTC and to confirm the associated thyroid pathology.

The study has been approved by the Ethics Committee of "Grigore T. Popa" University of Medicine and Pharmacy Iasi, complying with the ethical standards of Helsinki declaration that require the patients' informed consent on the usage of their biologic material.
2.2. Immunohistochemistry. For each case, a representative paraffin-embedded block has been chosen, and $3 \mu \mathrm{m}$ sections have been cut and have been displayed on electrostatically charged polylysine-coated slides.

Tissue samples were dewaxed in xylene and rehydrated in 3 baths of alcohol with progressive decreasing concentrations. Heat induced epitope retrieval technique was used for antigen retrieval. The slides were immersed in sodium citrate $\mathrm{pH}$ 6 and boiled in water bath at $98^{\circ} \mathrm{C}$ for 30 minutes. After cooling at room temperature and inhibition of endogenous peroxidase activity, the samples have been incubated with anti-periostin polyclonal antibody (Santa Cruz, Biotechnology Inc., Santa Cruz, USA) dilution 1:100, overnight at $4^{\circ} \mathrm{C}$. Immunoreaction has been amplified with the suitable secondary and tertiary antibodies of the LSAB-HRP complex (Dako, Carpinteria, USA) and developed with $3,3^{\prime}$ diaminobenzidine tetrahydrochloride chromogen (DakoCytomation, Carpinteria, USA); the positive reaction has been considered in the presence of a brown cytoplasmic stain. Positive and negative controls have been simultaneously run.

2.3. Semiquantitative Assessment. PN expression has been separately assessed in tumor epithelial cells and in intratumoral stroma, using adapted semiquantitative scores based on literature reports $[25,53,54]$. The corresponding nontumoral thyroid tissue within each PTC specimen has been constantly evaluated. This step allowed us to establish the basal level of thyroid tissue PN immunoreaction, considering the staining of the follicular cells within these areas as absent or weak $(+)$. We have evaluated the staining intensity in the tumor cellular component - I (0 when absent, 1 for weak $(+), 2$ for moderate $(++)$, and 3 for strong $(+++)$ intensity, resp.) and percentage of positive tumor cells $-P(0$ for $<10 \%$, 1 for $10-30 \%, 2$ for $30-60 \%$, and 3 for $>60 \%$ positive cells, resp.). The final score has been obtained as a sum between $I$ and $P$, with a minimum value of 0 and a maximum one of 6 . We have considered the values between 0 and 3 as low score (corresponding to PN negative or weak expression) and those between 4 and 6 as high score (revealing a high PN expression). The stromal $\mathrm{PN}$ reaction has been quantified as 0 for no staining or less than $5 \%$ and 1 for $>5 \%$ of positive intratumoral stroma, respectively.

2.4. Statistical Analysis. Statistical analysis has been performed by GraphPad Prism software package (GraphPad Software, San Diego, CA, USA). The association between PN expression and clinicopathological characteristics has been analyzed by applying the $\chi^{2}$ test, whereas odds ratios (ORs) using logistic regression have been calculated to assess the correlation between $\mathrm{PN}$ and outcome variables for tumor aggressiveness. Statistically significant results have been considered when $p<0.05$.

\section{Results}

3.1. Clinicopathological Characteristics. A predominant female sex was observed in our study group, 41 cases $(82.0 \%)$, compared to male sex, 9 cases $(18.5 \%)$. The mean age at 
diagnosis was $48.24 \pm 14.70$ years (range $19-76$ years), $42.0 \%$ (21 patients) being diagnosed at young age, under 45 years. Mean tumor size was $2.18 \pm 1.36 \mathrm{~cm}$ (range $1.1-7.5 \mathrm{~cm}$ ). Multifocality was present in 34 cases $(68 \%)$. We noted lymphovascular invasion in 14 cases (28\%), extrathyroidal extension in 23 cases (46.0\%), and lymph node metastasis in 7 cases $(14 \%)$.

Based on TNM and AJCC criteria, the cases were staged as follows: 18 cases (36\%), stage I, 6 cases (12\%), stage II, 25 cases $(50 \%)$, stage III, and 1 case (2\%), stage IV.

Histologically, there were 10 cases $(20 \%)$ diagnosed as conventional PTC and 40 cases $(80 \%)$ as other variants of PTC (follicular, 21 cases (42\%), oncocytic, 8 cases (16\%), macrofollicular, 7 cases (14\%), and tall cell, 4 cases (8\%)).

\subsection{PN Expression}

3.2.1. Qualitative Assessment. PN immunopositivity has been noticed in both tumor cells and intratumoral stroma.

PN expression exhibited a predominantly cytoplasmic, perinuclear, finely granular pattern, in tumor cells. The distribution was predominantly homogenous, though some heterogenous areas were focally identified. The reaction intensity was predominantly moderate or strong.

The histological variants of PTC showed different patterns of PN immunoreaction. The immunoexpression was diffusely cytoplasmic, with weak apical or basal polarization, in conventional (Figure 1), follicular, and macrofollicular (Figure 2) variants. The tall cell variant was characterized by localized immunoexpression, with predominantly apical distribution, along with focal infranuclear positivity (Figure 3). The immunoreaction was predominantly negative or very weak in oncocytic variant (Figure 4).

The intratumoral stromal PN expression was variable within the histological variants of PTC, from strong positivity in fibroblasts and collagen fibers up to lack of expression.

PN expression has been negative or weak, exhibiting a homogenous and diffuse cytoplasmic distribution in the follicular cells of nonneoplastic thyroid tissue.

3.2.2. Semiquantitative Assessment. Tumor cells' PN expression has been evaluated as low score in 14 cases $(28.0 \%)$ and with high score in 36 cases (72.0\%) (Table 1). Intratumoral stroma exhibited PN negativity or weak expression in 16 cases (32.0\%), whereas the other 34 cases (68\%) showed PN strong positivity (Table 2).

3.2.3. Correlations with Clinicopathological Prognostic Factors. The results of the statistical analysis between PN (low versus high expression) in tumor cells and clinicopathological features are summarized in Table 1 . Statistically significant differences were registered only between PN immunoreaction and histological variants $(p=0.0002)$. A high PN score was more frequently noted in conventional subtype than in oncocytic subtype (OD $=105$, CI 3.73-2948.28, $p=0.0062$ ).

Table 2 synthesizes the correlation between PN stromal expression (negative versus positive) and clinicopathological features. Our results show significant differences between stromal PN immunoreaction and tumor stage (early versus advanced stages) ( $p=0.04)$ and extrathyroidal extension $(p=0.008)$. Moreover, a high PN score was more frequently observed in advanced tumor stage (OR 0.28 , 95\% CI $0.07-0.99 ; p=0.0491)$ and in the occurrence of extrathyroidal extension (OR 0.16, CI 0.03-0.67, $p=0.0124$ )

We have also noted a very close value to the statistical significant $p$ value for the lymph node metastasis.

\section{Discussion}

PN is encoded by a gene located on chromosome 13 (13q13.3), in humans [55]. Structurally, it is formed by one N-terminal constant domain, one cysteine-rich domain (EMILIN-like), four fasciclin-repetitive-Fas domains, and one C-terminal hydrophilic domain exhibiting a variable structure according to the isoform $[3,4,55]$.

Currently, eight PN isoforms are known, only five of them being sequenced and identified in different tissues: isoform 1 or (a) in osteosarcoma, isoform 2 or (b) in human placenta, isoform 3 or (c) in ovarian carcinoma, and 2 (b), 4 (d), and 5 (e) in either normal or tumoral urinary bladder [3, 8, 56-58].

Different PN isoforms may variably influence ECM fibrillogenesis [59] but it is still unknown if their effect on ECM increases the invasiveness or metastatic potential $[13,60,61]$.

During the last 15 years, several papers provided evidences that support PN involvement in different malignancies. According to these studies, stromal PN expression is a negative prognostic factor for patients' survival [13, 28, 32, 41, 42 ] and, in association with epithelial PN, is significantly correlated with different clinicopathological prognostic factors $[11,13,20,35,44,47,62,63]$. PN involvement in the epithelialmesenchymal transition (EMT) has been also a matter of research interest, due to its potential therapeutic target value $[8,13,39,64-66]$. Therefore, PN expression was analyzed in correlation with EMT (vimentin, elastin, and collagen) and angiogenesis specific markers, demonstrating its involvement as a promoter of this process $[12,15,39,63,67]$.

Few papers addressed PN in thyroid tumors, predominantly using techniques of molecular biology (cDNA microarrays and real-time PCR) [58, 68-70]. Eight hperiostin isoforms have been identified in both thyroid carcinoma and in corresponding nonneoplastic tissues, all of them being related to thyroid carcinogenesis, invasion, or lymph node metastasis, regardless of differences between their expression pattern [58]. A high PN gene expression is associated with aggressive and poorly differentiated PTCs [68] and is correlated with specific morphological cellular features (loss of polarization and cohesiveness) registered in the invasive front of the tumor [69]. Only one of the four studies from literature has also analyzed PN immunoexpression, within a rather limited number of cases (10 normal thyroids, 10 follicular adenomas, 10 follicular thyroid carcinomas, and 10 PTCs samples, resp.) [70]. No PN staining has been noticed in normal thyroid tissue, in follicular adenoma, and in follicular thyroid carcinoma, and only 4 cases from a total of 10 PTCs showed a diffuse cytoplasmic immunoreaction [70]. 


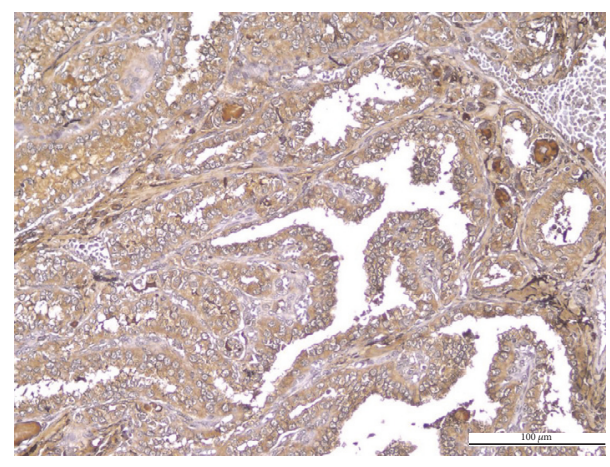

FIGURE 1: Conventional PTC. Positive PN in tumor cells: diffuse cytoplasmic positive immunoreaction of moderate intensity; negative $\mathrm{PN}$ in intratumoral stroma (IHC anti-PN, $\times 200$ ).

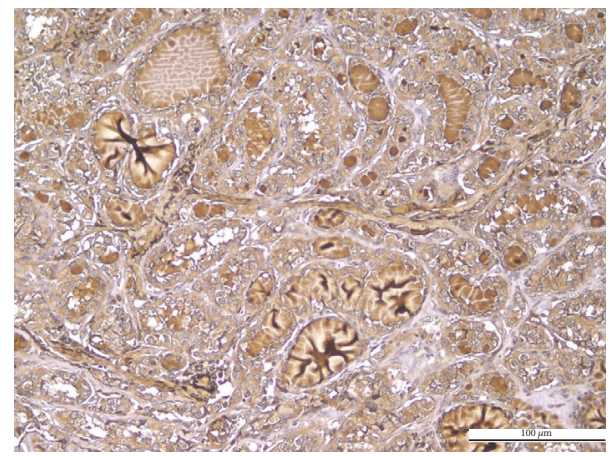

FIgure 2: Macrofollicular PTC. Positive PN in tumor cells: diffuse cytoplasmic immunoreaction of moderate intensity; negative $\mathrm{PN}$ in intratumoral stroma (IHC anti-PN, ×200).

Within this context, the present study provides new data regarding the specific PN immunoexpression in epithelial tumor cells and intratumoral stroma, in different histological subtypes of PTC.

To the best of our knowledge, this is the first report of qualitative differences in epithelial and stromal PN expression between conventional, follicular, macrofollicular, tall cell, and oncocytic subtypes. Thus, the idea that PN may be tissue-specific [11] is strengthened by supplementary evidences of its heterogeneity, reported in different histological subtypes of a specific tumor, such as clear cell, papillary, and chromophobe renal cell carcinoma types [33], and conventional and nonconventional osteosarcoma subtypes [71].

The pivotal role of PN synthesis in different malignancies is currently under scrutiny, by comparing the involvement of tumor epithelial cells with that of the tumor stromal component. As a consequence, it has been hypothesized that PN acts in a cell-type-dependent manner related to its expression in stromal versus epithelial cells, as a result of the activity of different PN terminal regions [13].

This hypothesis has been the starting point of our work which has individually quantified PN immunoexpression in tumor cells and in tumor stroma, respectively. We have additionally refined the reported scores already used for PN

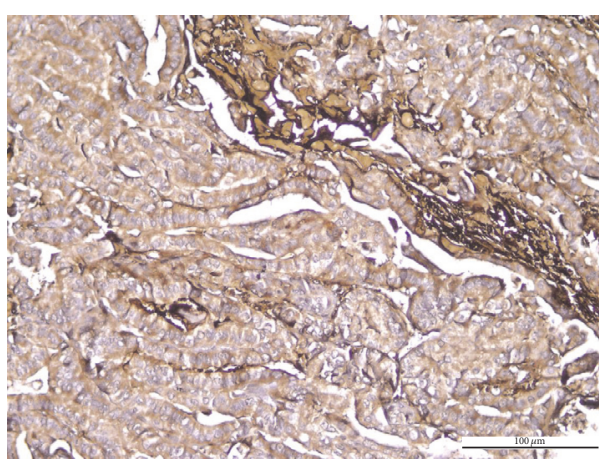

Figure 3: Tall cell PTC. Positive cytoplasmic PN, exhibiting focal apical and basal immunoreaction of moderate intensity; positive $\mathrm{PN}$ in intratumoral stroma (IHC anti-PN, ×200).

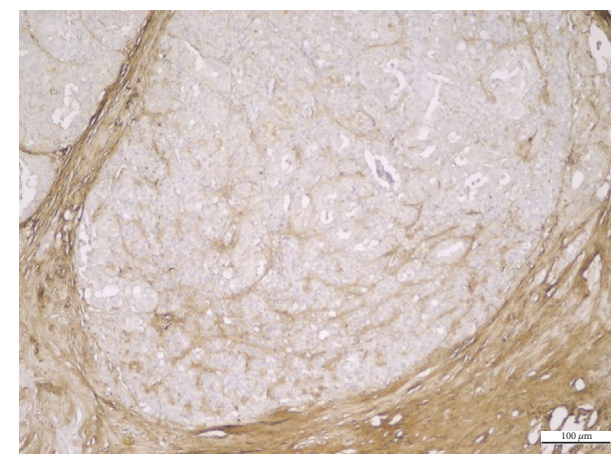

FIgURE 4: Oncocytic PTC. Negative PN expression in tumor epithelial cells and positive PN expression in tumor stroma (IHC anti-PN, $\times 200$ ).

assessment $[25,53,54]$, considering both the percentage of positive cells and the reaction intensity, using a threshold to label the investigated cases into low and high score categories. This modality of semiquantitative evaluation, based on a specific algorithm, has not been yet applied in thyroid tumor pathology.

Our study showed a heterogeneity of PN stromal immunoexpression, comparable to other malignancies reporting either PN positivity $[19,22,23,49,64]$ or PN negativity [72]. The most papers have reported that stromal PN has a more aggressive potential than the epithelial PN. This aggressiveness can be attributed to the capacity of the PN produced by the stromal components to act not only by intracellular signaling pathways but also by its fibrillogenic potential within ECM, its C-terminal region interacting with ECM molecules $[73,74]$.

Our results support the dominant protumorigenic role of stromal PN, while epithelial PN action is less evident. We found that the high stromal PN expression is significantly associated with an advanced tumor stage and extrathyroidal extension. Similar results are also reported in renal cell carcinoma [31,33], prostate [13, 27, 28], penile [75], and breast cancer $[20,23]$. There are no available literature data about the stromal PN profile in thyroid tumors. 
TABLE 1: PN expression in tumor epithelial cells and clinicopathological characteristics of PTC.

\begin{tabular}{|c|c|c|c|c|c|c|c|c|}
\hline \multirow{3}{*}{ Clinicopathologic features } & \multirow{2}{*}{\multicolumn{2}{|c|}{ Case number }} & \multicolumn{4}{|c|}{$\mathrm{PN}$} & \multirow{3}{*}{$\begin{array}{c}\chi^{2} \\
\text { p value }\end{array}$} & \multirow{3}{*}{$\begin{array}{c}\text { OR } \\
(95 \% \mathrm{CI})\end{array}$} \\
\hline & & & \multicolumn{2}{|c|}{ Low score } & \multicolumn{2}{|c|}{ High score } & & \\
\hline & $\#$ & $\%$ & $\#$ & $\%$ & $\#$ & $\%$ & & \\
\hline \multicolumn{9}{|l|}{$\operatorname{Sex}$} \\
\hline Female & 41 & 82 & 12 & 29.27 & 29 & 70.73 & \multirow{2}{*}{$p=0.6699$} & \multirow{2}{*}{$\begin{array}{c}0.69 \\
(0.12-3.81)\end{array}$} \\
\hline Male & 9 & 18 & 2 & 22.22 & 7 & 77.78 & & \\
\hline \multicolumn{9}{|l|}{ Age } \\
\hline$<45$ & 21 & 42 & 7 & 33.33 & 14 & 66.67 & \multirow{2}{*}{$p=0.4748$} & \multirow{2}{*}{$\begin{array}{c}0.63 \\
(0.18-2.20)\end{array}$} \\
\hline$>45$ & 29 & 58 & 7 & 24.14 & 22 & 75.86 & & \\
\hline \multicolumn{9}{|l|}{ Tumor stage } \\
\hline Stages I, II & 24 & 48 & 7 & 29.17 & 17 & 70.83 & \multirow{2}{*}{$p=0.8599$} & \multirow{2}{*}{$\begin{array}{c}0.89 \\
(0.26-3.07)\end{array}$} \\
\hline Stages III, IV & 26 & 52 & 7 & 26.92 & 19 & 73.08 & & \\
\hline \multicolumn{9}{|l|}{ Histologic subtype } \\
\hline Conventional & 10 & 20 & 0 & 0 & 10 & 100 & \multirow{5}{*}{$p=0.0002$} & 10.86 \\
\hline Follicular & 21 & 42 & 7 & 33.33 & 14 & 66.67 & & $(0.55-211.91)$ \\
\hline Macrofollicular & 7 & 14 & 0 & 0 & 7 & 100 & & $\begin{array}{c}1.4 \\
(0.02-78.80)\end{array}$ \\
\hline Tall cells & 4 & 8 & 0 & 0 & 4 & 100 & & $\begin{array}{c}1.00 \\
(0.24-4.13)\end{array}$ \\
\hline Oncocytic & 8 & 16 & 7 & 87.5 & 1 & 12.5 & & $\begin{array}{c}105.00 \\
(3.73-2948.28) \\
\end{array}$ \\
\hline \multicolumn{9}{|l|}{ Multifocality } \\
\hline Yes & 34 & 68 & 10 & 29.41 & 24 & 70.59 & \multirow{2}{*}{$p=0.7459$} & \multirow{2}{*}{$\begin{array}{c}0.8 \\
(0.20-3.08)\end{array}$} \\
\hline No & 16 & 32 & 4 & 25 & 12 & 75 & & \\
\hline \multicolumn{9}{|l|}{ Tumor size } \\
\hline$<2.18 \mathrm{~cm}$ & 35 & 70 & 10 & 28.57 & 25 & 71.43 & \multirow{2}{*}{$p=0.8907$} & \multirow{2}{*}{$\begin{array}{c}0.90 \\
(0.23-3.53)\end{array}$} \\
\hline$>2.18 \mathrm{~cm}$ & 15 & 30 & 4 & 26.67 & 11 & 73.33 & & \\
\hline \multicolumn{9}{|l|}{ Lymphovascular invasion } \\
\hline Absent & 36 & 72 & 12 & 33.33 & 24 & 66.67 & \multirow{2}{*}{$p=0.1780$} & \multirow{2}{*}{$\begin{array}{c}0.33 \\
(0.06-1.73)\end{array}$} \\
\hline Present & 14 & 28 & 2 & 14.29 & 12 & 85.71 & & \\
\hline \multicolumn{9}{|l|}{ Lymph node metastasis } \\
\hline Absent & 43 & 86 & 12 & 27.91 & 31 & 72.09 & & 1.03 \\
\hline Present & 7 & 14 & 2 & 28.57 & 5 & 71.43 & $p=0.9710$ & $(0.17-6.06)$ \\
\hline Extrathyroidal invasion & & & & & & & & \\
\hline Absent & 27 & 54 & 8 & 29.63 & 19 & 70.37 & & 0.83 \\
\hline Present & 23 & 46 & 6 & 26.09 & 17 & 73.91 & $=0.7810$ & $(0.24-2.90)$ \\
\hline
\end{tabular}

$\chi^{2}$ : chi-square test; OR: odd ratio; CI: confidence interval.

On the other hand, PN overexpression in tumor epithelial cells was correlated with specific histological PTC variants, the highest risk being registered for the conventional subtype in comparison to the oncocytic one. Our data are supplementing other results in the mainstream publications. Strictly referring to the thyroid pathology, the single published paper on PN immunoexpression in PTC [70] reports a correlation between $\mathrm{PN}$ overexpression and clinicopathological features (i.e., extrathyroidal invasion, distant metastasis, and higher grade staging).

Despite the small number of cases, the authors outline the correlation between PN, ETM, and an aggressive tumor behavior [70]. Moreover, they consider that $\mathrm{PN}$ could be a stronger negative prognostic marker than $\mathrm{B}$ RAF, regardless of B-RAF mutation [70]. In other types of malignancies, comparable relationships are demonstrated in renal cell carcinoma (mainly for clear cell subtype) where a greater tumor epithelial PN expression is significantly associated with sarcomatoid differentiation, higher tumor stage, lymph node metastases, and poor overall survival [32, 33] and also in hepatocellular carcinoma, where PN correlates with microvascular invasion, multiple tumors, and advanced tumor stage $[41,42]$.

Taken together, our results are consistent with the complex framework of controversies regarding $\mathrm{PN}$ role in carcinogenesis, particularly for the thyroid location, and 
TABLE 2: PN expression in intratumor stroma and clinicopathological characteristics of PTC.

\begin{tabular}{|c|c|c|c|c|c|c|c|c|}
\hline \multirow{3}{*}{ Clinicopathologic features } & \multirow{2}{*}{\multicolumn{2}{|c|}{ Case number }} & \multicolumn{4}{|c|}{$\mathrm{PN}$} & \multirow{3}{*}{$\begin{array}{c}\chi^{2} \\
\text { p value }\end{array}$} & \multirow{3}{*}{$\begin{array}{c}\text { OR } \\
(95 \% \mathrm{CI})\end{array}$} \\
\hline & & & \multicolumn{2}{|c|}{ Low score } & \multicolumn{2}{|c|}{ High score } & & \\
\hline & $\#$ & $\%$ & $\#$ & $\%$ & $\#$ & $\%$ & & \\
\hline \multicolumn{9}{|l|}{$\operatorname{Sex}$} \\
\hline Female & 41 & 82 & 13 & 31.71 & 28 & 68.29 & \multirow{2}{*}{$p=0.9246$} & \multirow{2}{*}{$\begin{array}{c}1.07 \\
(0.23-4.99)\end{array}$} \\
\hline Male & 9 & 18 & 3 & 33.33 & 6 & 66.67 & & \\
\hline \multicolumn{9}{|l|}{ Age } \\
\hline$<45$ & 21 & 42 & 5 & 23.81 & 16 & 76.19 & \multirow{2}{*}{$p=0.2907$} & \multirow{2}{*}{$\begin{array}{c}1.05 \\
(0.55-6.84)\end{array}$} \\
\hline$>45$ & 29 & 58 & 11 & 37.93 & 18 & 62.07 & & \\
\hline \multicolumn{9}{|l|}{ Tumor stage } \\
\hline Stages I, II & 24 & 48 & 11 & 45.83 & 13 & 54.17 & \multirow{2}{*}{$p=0.0439$} & \multirow{2}{*}{$\begin{array}{c}0.28 \\
(0.07-0.99)\end{array}$} \\
\hline Stages III, IV & 26 & 52 & 5 & 19.23 & 21 & 80.77 & & \\
\hline \multicolumn{9}{|l|}{ Histologic subtype } \\
\hline Conventional & 10 & 20 & 5 & 50 & 5 & 50 & \multirow{5}{*}{$p=0.7522$} & \multirow{2}{*}{$\begin{array}{c}0.40 \\
(0.08-1.90)\end{array}$} \\
\hline Follicular & 21 & 42 & 6 & 28.57 & 15 & 71.43 & & \\
\hline Macrofollicular & 7 & 14 & 2 & 28.57 & 5 & 71.43 & & $\begin{array}{c}1.00 \\
(0.15-6.64)\end{array}$ \\
\hline Tall cells & 4 & 8 & 1 & 25 & 3 & 75 & & $\begin{array}{c}3.00 \\
(0.22-39.60)\end{array}$ \\
\hline Oncocytic & 8 & 16 & 2 & 25 & 6 & 75 & & $\begin{array}{c}1.20 \\
(0.12-11.86) \\
\end{array}$ \\
\hline \multicolumn{9}{|l|}{ Multifocality } \\
\hline No & 34 & 68 & 13 & 38.24 & 21 & 61.76 & \multirow{2}{*}{$p=0.1683$} & \multirow{2}{*}{$\begin{array}{c}0.37 \\
(0.08-1.56)\end{array}$} \\
\hline Yes & 16 & 32 & 3 & 18.75 & 13 & 81.25 & & \\
\hline \multicolumn{9}{|l|}{ Tumor size } \\
\hline$<2.18 \mathrm{~cm}$ & 35 & 70 & 9 & 25.71 & 26 & 74.29 & \multirow{2}{*}{$p=0.1455$} & \multirow{2}{*}{$\begin{array}{c}2.52 \\
(0.71-8.96)\end{array}$} \\
\hline$>2.18 \mathrm{~cm}$ & 15 & 30 & 7 & 46.67 & 8 & 53.33 & & \\
\hline \multicolumn{9}{|l|}{ Lymphovascular invasion } \\
\hline Absent & 36 & 72 & 13 & 36.11 & 23 & 63.89 & \multirow{2}{*}{$p=0.3176$} & \multirow{2}{*}{$\begin{array}{c}0.48 \\
(0.11-2.04)\end{array}$} \\
\hline Present & 14 & 28 & 3 & 21.43 & 11 & 78.57 & & \\
\hline Lymph node metastasis & & & & & & & & \\
\hline Absent & 43 & 86 & 16 & 37.21 & 27 & 62.79 & & 0.11 \\
\hline Present & 7 & 14 & 0 & 0 & 7 & 100 & $p=0.0503$ & $(0.006-2.07)$ \\
\hline Extrathyroidal invasion & & & & & & & & \\
\hline Absent & 27 & 54 & 13 & 48.15 & 14 & 51.85 & & 0.16 \\
\hline Present & 23 & 46 & 3 & 13.04 & 20 & 86.96 & $p=0.008$ & $(0.03-0.67)$ \\
\hline
\end{tabular}

$\chi^{2}$ : chi-square test; OR: odd ratio; CI: confidence interval.

support the interest in understanding its relationship with different tumor behaviors. Further research is needed for the validation of $\mathrm{PN}$ current status as a promising biomarker.

\section{Conclusions}

Our study demonstrates a wide variability of PN expression in PTC, both in tumor epithelial component and in tumor stroma. High stromal rather than epithelial PN expression is associated with an aggressive tumor behavior. These results support PN involvement in tumor progression and its possible use as a prognostic marker.

\section{Conflicts of Interest}

The authors declare that they have no conflicts of interest.

\section{References}

[1] V. A. LiVosi, J. Albores-Saavedra, S. L. Asa et al., "Papillary carcinoma," in World Health Organization Classification of Tumours. Pathology and Genetics. Tumours of Endocrine Organs, pp. 57-66, IARC Press, Lyon, France, 2004.

[2] S. Erhamamci, M. Reyhan, N. E. Kocer, G. N. Nursal, N. Torun, and A. F. Yapar, "Simultaneous occurrence of medullary and differentiated thyroid carcinomas. Report of 4 cases and brief 
review of the literature," Hellenic Journal of Nuclear Medicine, vol. 17, no. 2, pp. 148-152, 2014.

[3] S. Takeshita, R. Kikuno, K. Tezuka, and E. Amann, "Osteoblastspecific factor 2: cloning of a putative bone adhesion protein with homology with the insect protein fasciclin I," Biochemical Journal, vol. 294, no. 1, pp. 271-278, 1993.

[4] K. Horiuchi, N. Amizuka, S. Takeshita et al., "Identification and characterization of a novel protein, periostin, with restricted expression to periosteum and periodontal ligament and increased expression by transforming growth factor $\beta$," Journal of Bone and Mineral Research, vol. 14, no. 7, pp. 12391249, 1999.

[5] R. A. Norris, R. A. Moreno-Rodriguez, Y. Sugi et al., "Periostin regulates atrioventricular valve maturation," Developmental Biology, vol. 316, no. 2, pp. 200-213, 2008.

[6] D. W. Hamilton, "Functional role of periostin in development and wound repair: implications for connective tissue disease," Journal of Cell Communication and Signaling, vol. 2, no. 1-2, pp. 9-17, 2008.

[7] K. Ruan, S. Bao, and G. Ouyang, "The multifaceted role of periostin in tumorigenesis," Cellular and Molecular Life Sciences, vol. 66, no. 14, pp. 2219-2230, 2009.

[8] L. Gillan, D. Matei, D. A. Fishman, C. S. Gerbin, B. Y. Karlan, and D. D. Chang, "Periostin secreted by epithelial ovarian carcinoma is a ligand for alpha(V)beta(3) and alpha(V)beta (5) integrins and promotes cell motility," Cancer Research, vol. 62, no. 18, pp. 5358-5364, 2002.

[9] I. T. Tai, M. Dai, and L. B. Chen, "Periostin induction in tumor cell line explants and inhibition of in vitro cell growth by antiperiostin antibodies," Carcinogenesis, vol. 26, no. 5, pp. 908-915, 2005.

[10] Y. Kudo, B. S. M. S. Siriwardena, H. Hatano, I. Ogawa, and T. Takata, "Periostin: Novel diagnostic and therapeutic target for cancer," Histology and Histopathology, vol. 22, no. 10-12, pp. 1167-1174, 2007.

[11] P. V. Nuzzo, G. Buzzatti, F. Ricci et al., "Periostin: A novel prognostic and therapeutic target for genitourinary cancer?" Clinical Genitourinary Cancer, vol. 12, no. 5, pp. 301-311, 2014.

[12] M. Zhu, M. S. Fejzo, L. Anderson et al., "Periostin promotes ovarian cancer angiogenesis and metastasis," Gynecologic Oncology, vol. 119, no. 2, pp. 337-344, 2010.

[13] L. Morra and H. Moch, "Periostin expression and epithelialmesenchymal transition in cancer: a review and an update," Virchows Archiv, vol. 459, no. 5, pp. 465-475, 2011.

[14] K. Ratajczak-Wielgomas and P. Dziegiel, "The role of periostin in neoplastic processes," Folia Histochemica et Cytobiologica, vol. 53, no. 2, pp. 120-132, 2015.

[15] B. S. M. S. Siriwardena, Y. Kudo, I. Ogawa et al., "Periostin is frequently overexpressed and enhances invasion and angiogenesis in oral cancer," British Journal of Cancer, vol. 95, no. 10, pp. 1396-1403, 2006.

[16] Y. Chang, T. C. Lee, J. C. Li et al., "Differential expression of osteoblast-specific factor 2 and polymeric immunoglobulin receptor genes in nasopharyngeal carcinoma," Head \& Neck, vol. 27, no. 10, pp. 873-882, 2005.

[17] Y. Kudo, I. Ogawa, S. Kitajima et al., "Periostin promotes invasion and anchorage-independent growth in the metastatic process of head and neck cancer," Cancer Research, vol. 66, no. 14, pp. 6928-6935, 2006.

[18] R. Shao, S. Bao, X. Bai et al., "Acquired expression of periostin by human breast cancers promotes tumor angiogenesis through up-regulation of vascular endothelial growth factor receptor 2 expression," Molecular and Cellular Biology, vol. 24, no. 9, pp. 3992-4003, 2004.

[19] F. Puglisi, C. Puppin, E. Pegolo et al., "Expression of periostin in human breast cancer," Journal of Clinical Pathology, vol. 61, no. 4, pp. 494-498, 2008.

[20] Y. Zhang, G. Zhang, J. Li, Q. Tao, and W. Tang, “The expression analysis of periostin in human breast cancer," Journal of Surgical Research, vol. 160, no. 1, pp. 102-106, 2010.

[21] D. Xu, H. Xu, Y. Ren et al., "Cancer stem cell-related gene periostin: a novel prognostic marker for breast cancer," PLoS ONE, vol. 7, no. 10, Article ID e46670, 2012.

[22] S. Contié, N. Voorzanger-Rousselot, J. Litvin, P. Clézardin, and P. Garnero, "Increased expression and serum levels of the stromal cell-secreted protein periostin in breast cancer bone metastases," International Journal of Cancer, vol. 128, no. 2, pp. 352-360, 2011.

[23] P. V. Nuzzo, A. Rubagotti, L. Zinoli, S. Salvi, S. Boccardo, and F. Boccardo, "The prognostic value of stromal and epithelial periostin expression in human breast cancer: Correlation with clinical pathological features and mortality outcome," BMC Cancer, vol. 16, no. 1, article no. 95, 2016.

[24] M. Zhu, R. E. Saxton, L. Ramos et al., "Neutralizing monoclonal antibody to periostin inhibits ovarian tumor growth and metastasis," Molecular Cancer Therapeutics, vol. 10, no. 8, pp. 15001508, 2011.

[25] K. U. Choi, J. S. Yun, I. H. Lee et al., "Lysophosphatidic acidinduced expression of periostin in stromal cells: Prognoistic relevance of periostin expression in epithelial ovarian cancer," International Journal of Cancer, vol. 128, no. 2, pp. 332-342, 2011.

[26] B. Y. Karlan, J. Dering, C. Walsh et al., "POSTN/TGFBIassociated stromal signature predicts poor prognosis in serous epithelial ovarian cancer," Gynecologic Oncology, vol. 132, no. 2, pp. 334-342, 2014.

[27] T. Tsunoda, B. Furusato, Y. Takashima et al., "The increased expression of periostin during early stages of prostate cancer and advanced stages of cancer stroma," The Prostate, vol. 69, no. 13, pp. 1398-1403, 2009.

[28] V. Tischler, F. R. Fritzsche, P. J. Wild et al., "Periostin is upregulated in high grade and high stage prostate cancer," $B M C$ Cancer, vol. 10, article no. 273, 2010.

[29] C. Sun, X. Zhao, K. Xu et al., "Periostin: A promising target of therapeutical intervention for prostate cancer," Journal of Translational Medicine, vol. 9, no. 1, article no. 99, 2011.

[30] P. V. Nuzzo, A. Rubagotti, L. Zinoli et al., "Prognostic value of stromal and epithelial periostin expression in human prostate cancer: correlation with clinical pathological features and the risk of biochemical relapse or death," BMC Cancer, vol. 12, article 625, 2012.

[31] V. Castronovo, D. Waltregny, P. Kischel et al., "A chemical proteomics approach for the identification of accessible antigens expressed in human kidney cancer," Molecular \& Cellular Proteomics, vol. 5, no. 11, pp. 2083-2091, 2006.

[32] C. Dahinden, B. Ingold, P. Wild et al., "Mining tissue microarray data to uncover combinations of biomarker expression patterns that improve intermediate staging and grading of clear cell renal cell cancer," Clinical Cancer Research, vol. 16, no. 1, pp. 88-98, 2010.

[33] L. Morra, M. Rechsteiner, S. Casagrande et al., "Relevance of periostin splice variants in renal cell carcinoma," The American Journal of Pathology, vol. 179, no. 3, pp. 1513-1521, 2011. 
[34] P. Baril, R. Gangeswaran, P. C. Mahon et al., "Periostin promotes invasiveness and resistance of pancreatic cancer cells to hypoxia-induced cell death: role of the $\beta_{4}$ integrin and the PI3k pathway," Oncogene, vol. 26, no. 14, pp. 2082-2094, 2007.

[35] Q.-W. Ben, X.-L. Jin, L. Jun, X. Cai, F. Yuan, and Y.-Z. Yuan, "Periostin, a matrix specific protein, is associated with proliferation and invasion of pancreatic cancer," Oncology Reports, vol. 25, no. 3, pp. 709-716, 2011.

[36] J.-S. Li, G.-W. Sun, X.-Y. Wei, and W.-H. Tang, "Expression of periostin and its clinicopathological relevance in gastric cancer," World Journal of Gastroenterology, vol. 13, no. 39, pp. 5261-5266, 2007.

[37] Y. Kikuchi, A. Kunita, C. Iwata et al., “The niche component periostin is produced by cancer-associated fibroblasts, supporting growth of gastric cancer through ERK activation," The American Journal of Pathology, vol. 184, no. 3, pp. 859-870, 2014.

[38] H. Lv, R. Liu, J. Fu et al., "Epithelial cell-derived periostin functions as a tumor suppressor in gastric cancer through stabilizing p53 and E-cadherin proteins via the Rb/E2F1/p14ARF/Mdm2 signaling pathway," Cell Cycle, vol. 13, no. 18, pp. 2962-2974, 2014.

[39] S. Bao, G. Ouyang, X. Bai et al., "Periostin potently promotes metastatic growth of colon cancer by augmenting cell survival via the Akt/PKB pathway," Cancer Cell, vol. 5, no. 4, pp. 329-339, 2004.

[40] Z.-M. Xiao, X.-Y. Wang, and A.-M. Wang, "Periostin induces chemoresistance in colon cancer cells through activation of the PI3K/Akt/survivin pathway," Biotechnology and Applied Biochemistry, vol. 62, no. 3, pp. 401-406, 2015.

[41] M.-O. Riener, F. R. Fritzsche, C. Soll et al., "Expression of the extracellular matrix protein periostin in liver tumours and bile duct carcinomas," Histopathology, vol. 56, no. 5, pp. 600-606, 2010.

[42] S. Y. Jang, S. Y. Park, H. W. Lee et al., "The combination of periostin overexpression and microvascular invasion is related to a poor prognosis for hepatocellular carcinoma," Gut and Liver, vol. 10, no. 6, pp. 948-954, 2016.

[43] H. Sasaki, D. Auclair, I. Fukai et al., "Serum level of the periostin, a homologue of an insect cell adhesion molecule, as a prognostic marker in nonsmall cell lung carcinomas," Cancer, vol. 92, no. 4, pp. 843-848, 2001.

[44] A. Soltermann, V. Tischler, S. Arbogast et al., "Prognostic significance of epithelial-mesenchymal and mesenchymal-epithelial transition protein expression in non-small cell lung cancer," Clinical Cancer Research, vol. 14, no. 22, pp. 7430-7437, 2008.

[45] L. Morra, M. Rechsteiner, S. Casagrande et al., "Characterization of periostin isoform pattern in non-small cell lung cancer," Lung Cancer, vol. 76, no. 2, pp. 183-190, 2012.

[46] L.-Z. Hong, X.-W. Wei, J.-F. Chen, and Y. Shi, "Overexpression of periostin predicts poor prognosis in non-small cell lung cancer," Oncology Letters, vol. 6, no. 6, pp. 1595-1603, 2013.

[47] A. Schramm, I. Opitz, S. Thies et al., "Prognostic significance of epithelial-mesenchymal transition in malignant pleural mesothelioma," European Journal of Cardio-Thoracic Surgery, vol. 37, no. 3, pp. 566-572, 2010.

[48] H. Sasaki, Y. Sato, S. Kondo et al., "Expression of the periostin mRNA level in neuroblastoma," Journal of Pediatric Surgery, vol. 37, no. 9, pp. 1293-1297, 2002.

[49] B. Tian, Y. Zhang, and J. Zhang, "Periostin is a new potential prognostic biomarker for glioma," Tumor Biology, vol. 35, no. 6, pp. 5877-5883, 2014.
[50] W. Zhou, S. Q. Ke, Z. Huang et al., "Periostin secreted by glioblastoma stem cells recruits M2 tumour-associated macrophages and promotes malignant growth," Nature Cell Biology, vol. 17, no. 2, pp. 170-182, 2015.

[51] A. M. Mikheev, S. A. Mikheeva, A. D. Trister et al., "Periostin is a novel therapeutic target that predicts and regulates glioma malignancy," Neuro-Oncology, vol. 17, no. 3, pp. 372-382, 2015.

[52] F. L. Greene, D. L. Page, I. D. Fleming et al., Eds., AJCC Cancer Staging Handbook, Springer, New York, NY, USA, 6th edition, 2002.

[53] W. Jia, W. Wang, C.-S. Ji et al., "Coexpression of periostin and EGFR in patients with esophageal squamous cell carcinoma and their prognostic significance," OncoTargets and Therapy, vol. 9, pp. 5133-5142, 2016.

[54] P.-L. Sung, Y.-H. Jan, S.-C. Lin et al., "Periostin in tumor microenvironment is associated with poor prognosis and platinum resistance in epithelial ovarian carcinoma," Oncotarget, vol. 7, no. 4, pp. 4036-4047, 2016.

[55] J. Litvin, A.-H. Selim, M. O. Montgomery et al., "Expression and function of periostin-isoforms in bone," Journal of Cellular Biochemistry, vol. 92, no. 5, pp. 1044-1061, 2004.

[56] J. Litvin, S. Zhu, R. Norris, and R. Markwald, "Periostin family of proteins: Therapeutic targets for heart disease," Anatomical Record - Part A Discoveries in Molecular, Cellular, and Evolutionary Biology, vol. 287, no. 2, pp. 1205-1212, 2005.

[57] C. J. Kim, T. Isono, Y. Tambe et al., "Role of alternative splicing of periostin in human bladder carcinogenesis," International Journal of Oncology, vol. 32, no. 1, pp. 161-169, 2008.

[58] Y. Bai, M. Nakamura, G. Zhou et al., "Novel isoforms of periostin expressed in the human thyroid," Japanese Clinical Medicine, vol. 1, pp. 13-20, 2010.

[59] S. Hoersch and M. A. Andrade-Navarro, "Periostin shows increased evolutionary plasticity in its alternatively spliced region," BMC Evolutionary Biology, vol. 10, no. 1, article no. 30, 2010.

[60] A. Kudo, "Periostin in fibrillogenesis for tissue regeneration: Periostin actions inside and outside the cell," Cellular and Molecular Life Sciences, vol. 68, no. 19, pp. 3201-3207, 2011.

[61] S. J. Conway, K. Izuhara, Y. Kudo et al., "The role of periostin in tissue remodeling across health and disease," Cellular and Molecular Life Sciences, vol. 71, no. 7, pp. 1279-1288, 2014.

[62] K. Utispan, J. Sonongbua, P. Thuwajit et al., "Periostin activates integrin $\alpha 5 \beta 1$ through a PI3K/AKT-dependent, pathway in invasion of cholangiocarcinoma," International Journal of Oncology, vol. 41, no. 3, pp. 1110-1118, 2012.

[63] Y. Lv, W. Wang, W. Jia et al., "High-level expression of periostin is closely related to metastatic potential and poor prognosis of hepatocellular carcinoma," Medical Oncology, vol. 30, no. 1, pp. $1-9,2013$.

[64] P. Li, S. Oparil, W. Feng, and Y.-F. Chen, "Hypoxia-responsive growth factors upregulate periostin and osteopontin expression via distinct signaling pathways in rat pulmonary arterial smooth muscle cells," Journal of Applied Physiology, vol. 97, no. 4, pp. 1550-1558, 2004.

[65] W. Yan and R. Shao, "Transduction of a mesenchyme-specific gene periostin into $293 \mathrm{~T}$ cells induces cell invasive activity through epithelial-mesenchymal transformation," The Journal of Biological Chemistry, vol. 281, no. 28, pp. 19700-19708, 2006.

[66] C. J. Kim, K. Sakamoto, Y. Tambe, and H. Inoue, “Opposite regulation of epithelial-to-mesenchymal transition and cell invasiveness by periostin between prostate and bladder cancer 
cells," International Journal of Oncology, vol. 38, no. 6, pp. 17591766, 2011.

[67] Y. Kudo, S. Iizuka, M. Yoshida et al., "Periostin directly and indirectly promotes tumor lymphangiogenesis of head and neck cancer," PLoS ONE, vol. 7, no. 8, Article ID e44488, 2012.

[68] Ø. Fluge, O. Bruland, L. A. Akslen, J. R. Lillehaug, and J. E. Varhaug, "Gene expression in poorly differentiated papillary thyroid carcinomas," Thyroid, vol. 16, no. 2, pp. 161-175, 2006.

[69] Y. Bai, K. Kakudo, M. Nakamura et al., "Loss of cellular polarity/cohesiveness in the invasive front of papillary thyroid carcinoma and periostin expression," Cancer Letters, vol. 281, no. 2, pp. 188-195, 2009.

[70] C. Puppin, D. Fabbro, M. Dima et al., "High periostin expression correlates with aggressiveness in papillary thyroid carcinomas," Journal of Endocrinology, vol. 197, no. 2, pp. 401-408, 2008.

[71] F. Hu, W. Wang, H.-C. Zhou, and X.-F. Shang, "High expression of periostin is dramatically associated with metastatic potential and poor prognosis of patients with osteosarcoma," World Journal of Surgical Oncology, vol. 12, no. 1, article no. 287, 2014.

[72] N. Fukushima, Y. Kikuchi, T. Nishiyama, A. Kudo, and M. Fukayama, "Periostin deposition in the stroma of invasive and intraductal neoplasms of the pancreas," Modern Pathology, vol. 21, no. 8, pp. 1044-1053, 2008.

[73] R. A. Morris, B. Damon, V. Mironov et al., "Periostin regulates collagen fibrillogenesis and the biomechanical properties of connective tissues," Journal of Cellular Biochemistry, vol. 101, no. 3, pp. 695-711, 2007.

[74] G. Takayama, K. Arima, T. Kanaji et al., "Periostin: A novel component of subepithelial fibrosis of bronchial asthma downstream of IL-4 and IL-13 signals," The Journal of Allergy and Clinical Immunology, vol. 118, no. 1, pp. 98-104, 2006.

[75] S. Gunia, A. Jain, S. Koch et al., "Periostin expression correlates with pT-stage, grading and tumour size, and independently predicts cancer-specific survival in surgically treated penile squamous cell carcinomas," Journal of Clinical Pathology, vol. 66, no. 4, pp. 297-301, 2013. 


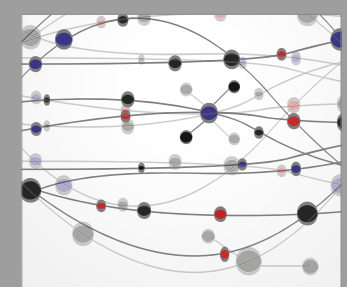

The Scientific World Journal
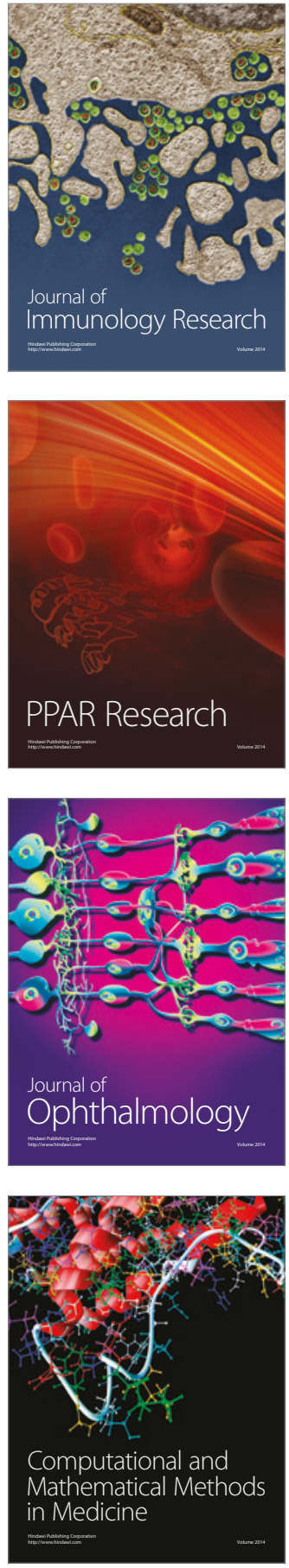

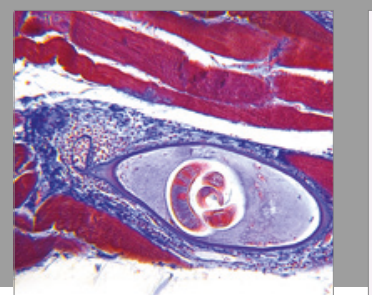

Gastroenterology Research and Practice
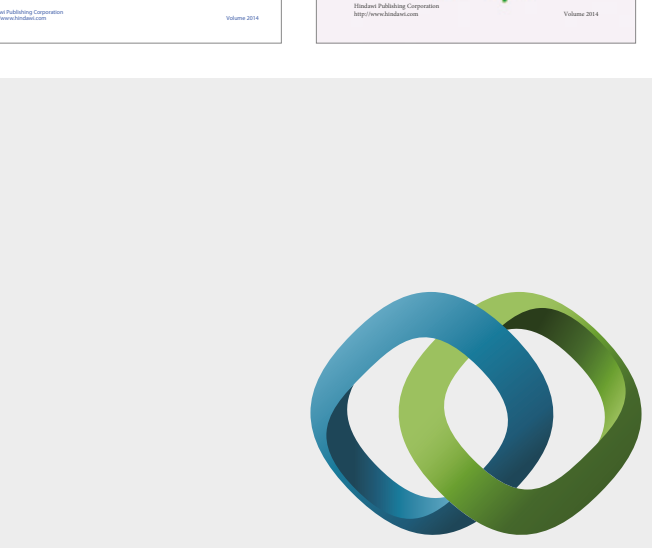

\section{Hindawi}

Submit your manuscripts at

https://www.hindawi.com
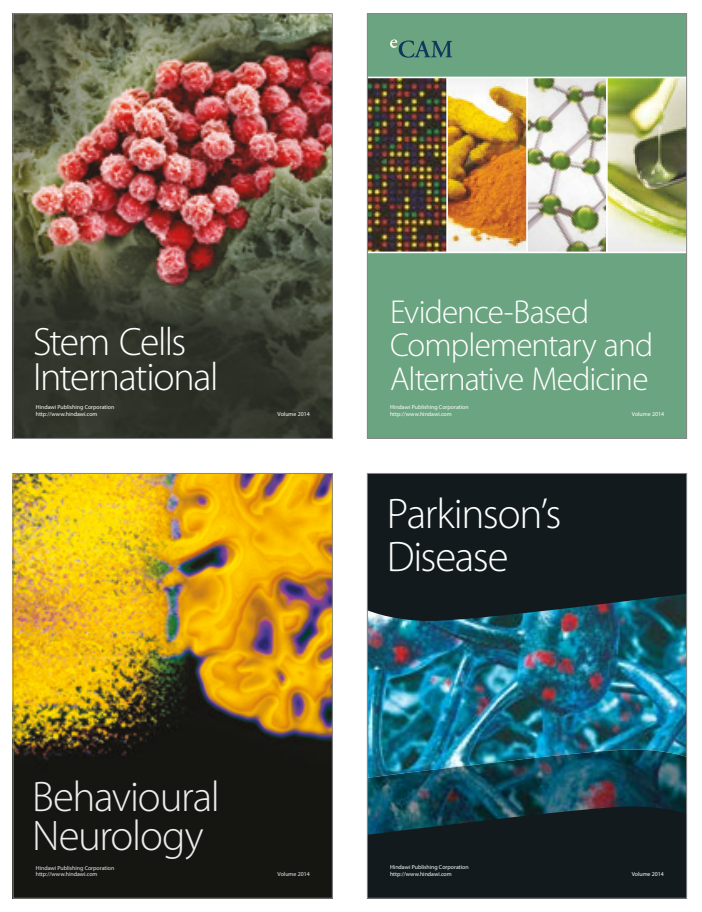
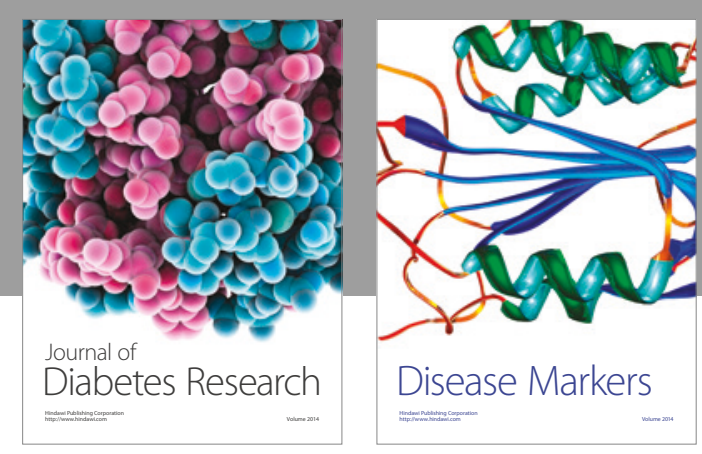

Disease Markers
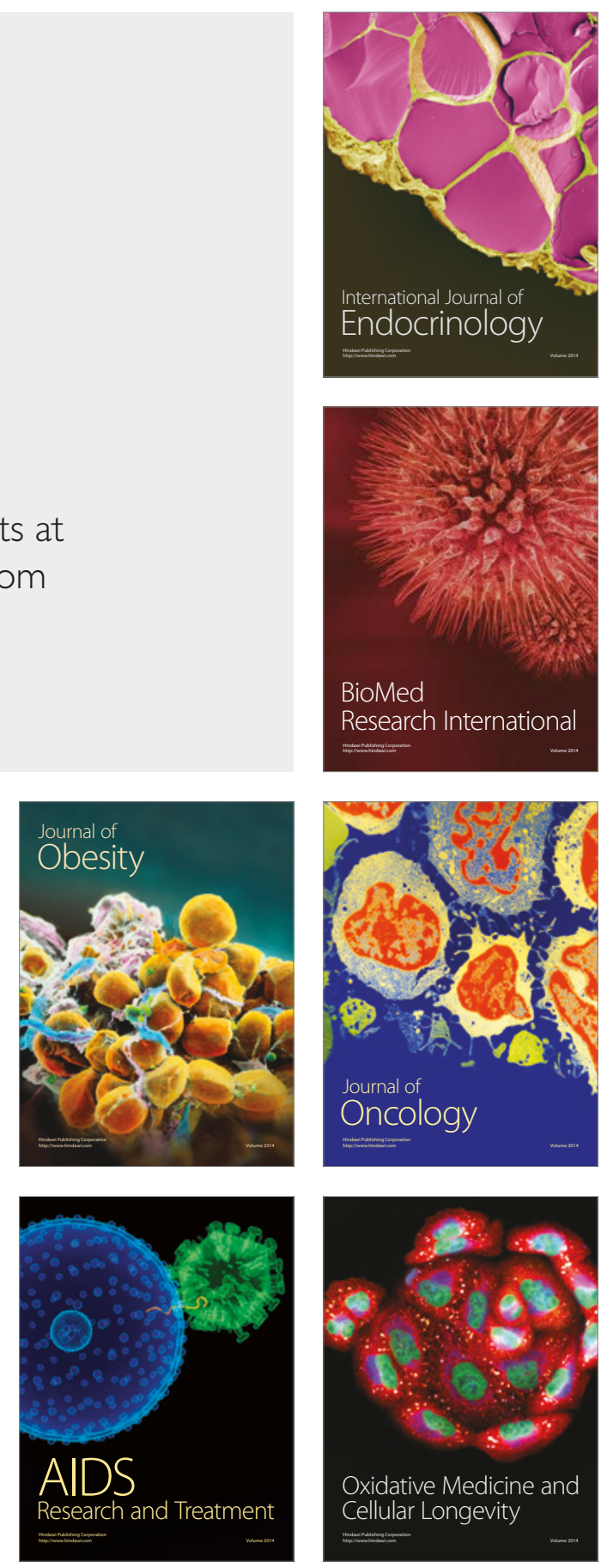